\title{
Jesus in Continuum
}

\author{
Ed. by Tom Holmén
}

[Jesus in Kontinuität.]

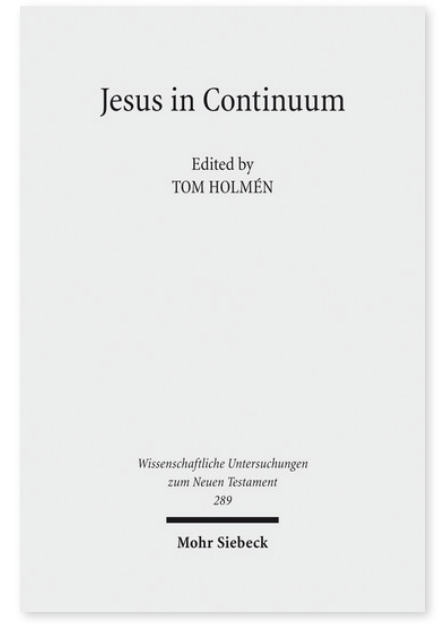

2012. XXVI, 492 Seiten. WUNT I 289

ISBN 978-3-16-152253-6

DOI 10.1628/978-3-16-152253-6

eBook PDF 149,00 €

ISBN 978-3-16-150683-3

Leinen $149,00 €$
Veröffentlicht auf Englisch.

Eines der Hauptmerkmale der aktuellen historischen Jesusforschung ist der Versuch, Jesus innerhalb des Judentums im 1. Jahrhundert zu positionieren. Vergleichsweise wenig Bedeutung wurde bisher der Frage beigemessen, ob oder wie überhaupt das Bild von Jesus innerhalb des jüdischen Kontextes auch zum geschichtlichen Einfluss und zur Rezeptionsgeschichte Jesu im frühen Christentum paßt und beiträgt. Tom Holmén plädiert dafür, dass die christliche Rezeptionsgeschichte Jesu einen angemessenen Stellenwert in der Forschung erhält. Die genaue Prüfung der Rezeption sollte nicht nur als Anhängsel einer sorgsameren Studie der Rolle Jesu innerhalb des Judentums betrachtet werden. Statt dessen sollte der Rezeption genauso große Beachtung geschenkt werden und sie sollte ein integrierter Teil der wissenschaftlichen Forschung sein. Jesus sollte also nicht mehr länger innerhalb des Judentums, sondern in der Kontinuität vom frühen Judentum bis zum frühen Christentum untersucht werden.

Tom Holmén Born 1963, 1999 ThD from Åbo Akademi University; currently adjunct professor of New Testament Exegetics at Åbo Akademi University and University of Helsinki.

\section{Jetzt bestellen:}

https://mohrsiebeck.com/buch/jesus-in-continuum-9783161522536?no_cache=1

order@mohrsiebeck.com

Telefon: +49 (0)7071-923-17

Telefax: $+49(0) 7071-51104$ 